\title{
Efluente de esgoto doméstico tratado e reutilizado como fonte hídrica alternativa para a produção de cana-de-açúcar
}

\author{
Cley A. S. de Freitas', Alexandre R. A. da Silva², Francisco M. L. Bezerra ${ }^{2}$, \\ Francisco S. B. Mota ${ }^{3}$, Luciana R. B. Gonçalves ${ }^{4}$ \& Emanuel M. Barros ${ }^{4}$
}

\begin{abstract}
RESUMO
Com base no consumo hídrico excessivo na produção agrícola e da expansão do cultivo da cana-de-açúcar impulsionada pela crescente demanda de etanol, tem-se questionado em relação a um uso mais racional da água de irrigação e ao reúso de água na produção agrícola. Desta forma objetivou-se, com o presente trabalho, avaliar os efeitos do reúso de efluente de esgoto doméstico tratado na irrigação da cana-deaçúcar. O estudo foi conduzido no Centro de Pesquisa sobre Tratamento e Reúso de Águas Residuárias, em Aquiraz, CE. O delineamento experimental adotado foi o de blocos ao acaso, no esquema de parcelas subdivididas, com quatro repetições. Nas parcelas avaliaram-se os efeitos de dois tipos de água (água potável e esgoto doméstico tratado); e nas subparcelas se alocaram cinco lâminas de irrigação baseadas em percentuais da evaporação medida em um tanque do tipo classe A (ECA). Concluiu-se que a água residuária proporcionou o maior potencial produtivo de colmos $\left(272,1 \mathrm{Mg} \mathrm{ha}^{-1}\right)$ e a maior densidade de plantas (126.000 plantas ha-1). O aumento das lâminas de irrigação proporcionou incrementos no potencial produtivo e na densidade de plantas, independente do tipo de água.
\end{abstract}

Palavras-chave: reúso de água, gotejamento, Saccharum officinarum L.

\section{Reuse of treated domestic sewage effluent as an alternative water source for the production of sugarcane}

\begin{abstract}
With the excessive consumption of water in agricultural production, and the expansion of the cultivation of sugarcane due to growing demand for ethanol, in this context, a rational use of water for irrigation and use of wastewater in agricultural production has been raised. Therefore, the objective of this study was to evaluate the effects of reuse of treated domestic sewage effluent for irrigation of sugarcane. The study was conducted at the Research Center on Treatment and Reuse of Wastewater, in Aquiraz, CE. The experimental design was randomized blocks in split plots with four replications. In the plots were evaluated the effects of two types of water (well water and treated domestic sewage); in the subplots five irrigation water depths were allocated, based on percentage of evaporation in a Class " $\mathrm{A}$ " tank. It can be concluded that wastewater provided the highest potential yield of stem $\left(272.1 \mathrm{Mg} \mathrm{ha}^{-1}\right)$ and higher plant density $\left(126,000\right.$ plants ha- $\left.{ }^{-1}\right)$. The increase in irrigation water depths provided increase in potential yield and plant density, regardless of the type of water.
\end{abstract}

Key words: water reuse, drip irrigation, Saccharum officinarum L.

${ }^{1}$ IFCE, Campus Tianguá, CE 075, s/n, CEP 62320-000, Tianguá, CE. Fone: (88) 3671-2299. E-mail: cleyanderson@ifce.edu.br ${ }^{2}$ DENA/UFC, Av. mister Hull, s/n, CEP 60440-554, Fortaleza, CE. Fone: (85) 3366-9758. E-mail: alexandre reuber@hotmail.com, mbezerra@ufc.br

${ }^{3}$ DEHA/UFC. Fone: (85) 3366-9624. E-mail:suetonio@ufc.br

${ }^{4}$ PGEQ/UFC, Av. mister Hull, s/n, CEP 60440-554, Fortaleza, CE. Fone: (85) 3366-9611. E-mail:Lrg@ufc.br, emanuel_brs@hotmail.com 


\section{INTRODUÇÃO}

Em escala mundial o Brasil se mantém como o maior produtor de cana-de-açúcar (Saccharum officinarum) com uma produção estimada em 514 milhões de toneladas por ano, seguido da Índia e da China, com 356 milhões e 106 milhões de toneladas, respectivamente. $\mathrm{O}$ nordeste brasileiro detém apenas $10,1 \%$ da produção nacional enquanto o estado do Ceará contribui com aproximadamente $0,03 \%$ da produção canavieira na região (Brasil, 2012). Esta baixa participação se deve principalmente às baixas e irregulares precipitações pluviométricas anuais registradas no nordeste, que se situam em torno de aproximadamente $750 \mathrm{~mm}$, sendo esta média anual inferior às exigências hídricas da cana-de-açúcar que se concentra no intervalo compreendido entre 1.400 e 2.000 $\mathrm{mm}$, como observado por pesquisadores (Sousa et al., 1999; Maule et al., 2001). Desta forma, a prática da irrigação se torna fundamental para a produção de cana-de-açúcar no Ceará.

Farias et al. (2009) observaram efeito significativo do uso da irrigação na produção de colmos, obtendo incremento de $28,26 \mathrm{Mg} \mathrm{ha}^{-1}$ quando comparado com a produção obtida em condições de sequeiro. Resultados semelhantes foram observados por Dantas Neto et al. (2006) com acréscimo de $21,67 \mathrm{Mg} \mathrm{ha}^{-1}$ na produção de colmos da cana irrigada, quando comparada com a de sequeiro.

Há uma forte correlação entre a lâmina de água disponibilizada à cultura e as variáveis que definem a qualidade de sua produção (Farias et al., 2009). Azevedo (2002) observou, para a variedade SP79-1011 com doze meses de cultivo nos tabuleiros costeiros da Paraíba, produtividades médias de 52, 79, 93 e $92 \mathrm{Mg} \mathrm{ha}^{-1}$, com as disponibilidades hídricas referentes a 609, 761, 905 e $1.043 \mathrm{~mm}$, respectivamente.

Embora haja tendência de incremento das variáveis produtivas com o aumento da disponibilidade hídrica no solo, o excesso de água também pode ser prejudicial à produção de colmos. Dantas Neto et al. (2006) observaram, trabalhando com a cana-de-açúcar sob diferentes níveis de irrigação e adubação, melhores resultados para as variáveis de produção: rendimento de colmos; conteúdo de sólidos solúveis totais (Brix) e etanol, de $104 \mathrm{Mg} \mathrm{ha}^{-1}, 18,67$ e 10,00\%, respectivamente, obtidos com a lâmina de irrigação de $1.164 \mathrm{~mm}$ e que os mesmos foram superiores aos observados com a máxima lâmina de irrigação $(1.343 \mathrm{~mm})$.

Com a expansão do cultivo da cana-de-açúcar impulsionada pelo aumento da demanda nacional por etanol e com o consumo hídrico excessivo da cultura, têm sido intensificadas, recentemente, pesquisas direcionadas à viabilidade do uso de águas residuárias para irrigação desta cultura. Freitas et al. (2012) observaram, trabalhando com a cana-de-açúcar em duas fontes hídricas, água potável e esgoto, maiores variáveis vegetativas para a cana-de-açúcar irrigada com esgoto doméstico tratado. De acordo com Deon et al. (2010) a irrigação da cana-de-açúcar, primeira soca, com efluente de esgoto doméstico tratado proporcionou incremento de até 19,84 $\mathrm{Mg} \mathrm{ha}^{-1}$ ao ser comparado com o rendimento obtido com o uso de água potável. Ainda segundo o autor, a irrigação baseada na ETc levou ao aporte de até $163,48 \mathrm{~kg} \mathrm{ha}^{-1} \mathrm{de} \mathrm{N}$.

Neste sentido objetivou-se, com o presente trabalho, avaliar os efeitos do reúso de efluente de esgoto doméstico tratado na irrigação da cana-de-açúcar visando avaliar o desempenho produtivo da cultura para a produção de etanol, em dois tipos de águas e cinco lâminas de irrigação.

\section{Material e Métodos}

O experimento foi conduzido entre os meses de maio de 2010 a agosto de 2011, no Centro de Pesquisa sobre Tratamento e Reúso de Águas Residuárias, mantido pela Companhia de Águas e Esgotos do Ceará (CAGECE) e a Universidade Federal do Ceará, localizado no município de Aquiraz, região metropolitana de Fortaleza, CE, com as seguintes coordenadas locais de referência $3^{\circ} 54^{\prime} 05^{\prime \prime}$ de latitude Sul, $38^{\circ} 23^{\prime} 28^{\prime \prime}$ de longitude, a Oeste de Greenwich e altitude média de 14,2 m. O clima da região, segundo Köppen, é classificado como Aw' correspondendo a Tropical chuvoso, com uma precipitação média anual de $1.379,9 \mathrm{~mm}$ e temperatura média anual de $27^{\circ} \mathrm{C}$.

Por ocasião da instalação do experimento foram coletadas amostras de solo da área experimental nas camadas $0-0,25$ e de 0,25-0,50 m; em seguida, tais amostras foram caracterizadas no Laboratório de Solos e Água do Departamento de Ciências do Solo da Universidade Federal do Ceará para caracterização dos atributos físico-hídricos e químicos (Tabelas 1 e 2 , respectivamente). $\mathrm{O}$ solo foi classificado como Argissolo, textura arenosa e relevo plano (EMBRAPA, 2006).

Tabela 1. Características físico-hídricas do solo da área experimental ${ }^{1}$

\begin{tabular}{|c|c|c|c|c|c|c|}
\hline \multirow{2}{*}{$\begin{array}{l}\text { Prof. } \\
\text { (m) }\end{array}$} & \multicolumn{2}{|c|}{$\begin{array}{r}\text { Densidade } \\
\left(\mathrm{kg} \mathrm{dm}^{-3}\right)\end{array}$} & \multirow{2}{*}{$\begin{array}{c}\mathrm{pH} \\
\text { água }\end{array}$} & \multicolumn{2}{|c|}{$\begin{array}{l}\text { Umidade do solo } \\
\left(\mathrm{m}^{-3} \mathrm{~m}^{-3}\right)-\mathrm{kPa}\end{array}$} & \multirow{2}{*}{$\begin{array}{c}\text { Classificação } \\
\text { textural }\end{array}$} \\
\hline & Solo & Partícula & & 33 & 1500 & \\
\hline $\begin{array}{r}0-0,25 \\
0,25-0,50\end{array}$ & $\begin{array}{l}1,52 \\
1,54\end{array}$ & & & 3,53 & & \\
\hline
\end{tabular}

${ }^{1}$ Análises realizadas no Laboratório de Solos e Água do Departamento de Ciências do Solo da UFC

A área total ocupada pelo experimento foi de $1248 \mathrm{~m}^{2}$.Cada unidade experimental foi composta de 4 linhas de plantas de $6 \mathrm{~m}$, espaçadas $1,2 \mathrm{~m}$, em que apenas as 2 linhas centrais foram consideradas úteis e as 2 externas, bordaduras. O delineamento experimental utilizado foi de blocos ao acaso, com parcelas subdivididas (split-plot) com dois tratamentos nas parcelas, cinco nas subparcelas, com quatro repetições. As parcelas se constituíram de dois tipos de água para irrigação (água potável AP; e efluente de esgoto doméstico tratado - E). Nas subparcelas avaliaram-se os efeitos de cinco lâminas de irrigação baseadas

Tabela 2 . Características químicas do solo da área experimental ${ }^{1}$

\begin{tabular}{|c|c|c|c|c|c|c|c|c|c|c|c|c|}
\hline Prof. & CEes & $\bar{N}$ & $\bar{C}$ & K & $\mathrm{Ca}$ & $\mathrm{Mg}$ & $\overline{A l}$ & $\mathrm{H}+\mathrm{Al}$ & $\mathrm{Na}$ & $S$ & CTC & M.0 \\
\hline (m) & $\left(\mathrm{dS} \mathrm{m}^{-1}\right)$ & $\left(\mathrm{g} \mathrm{kg}^{-1}\right)$ & $\left(\mathrm{g} \mathrm{kg}^{-1}\right)$ & & & & & $\left.\mathrm{kg}^{-1}\right)$ & & & & $\left(\mathrm{mg} \mathrm{kg}^{-1}\right)$ \\
\hline $0-0,25$ & 0,23 & 0,5 & 5,04 & 0,09 & 1,4 & 1,3 & 0,15 & 1,32 & 3 & 5,79 & 7,11 & 8,69 \\
\hline $0,25-0,50$ & 0,15 & 0,3 & 3,72 & 0,14 & 1.4 & 1,4 & 0,15 & 1,48 & 6 & 8,94 & 10,42 & c \\
\hline
\end{tabular}

${ }^{1}$ Análises realizadas no Laboratório de Solos e Água do Departamento de Ciências do Solo da UFC 
na evaporação medida em um tanque do tipo Classe "A" (ECA): $\mathrm{L} 1=50 \% \mathrm{ECA} ; \mathrm{L} 2=75 \%$ da ECA; L3 = 100\% da ECA; L4 $=125 \%$ da ECA e L $5=150 \%$ da ECA.

A variedade de cana-de-açúcar utilizada foi a SP71-6949 por ser adaptada ao clima da região Nordeste do Brasil, cuja cana-semente foi doada pela Empresa Ypioca, situada em Paraipaba, CE.

Iniciou-se o preparo do solo com uma roçagem seguida de uma gradagem cruzada. Os sulcos foram abertos manualmente com uma profundidade de aproximadamente $0,35 \mathrm{~m}$, espaçados 1,2 m. Conforme adotado por Silva et al. (2009a) e Dantas Neto et al. (2006) o plantio foi realizado com sobreposição total e ponta cabeça deixando-se uma média de

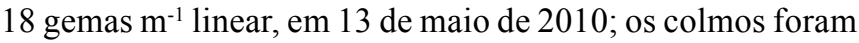
picados em rolete.

A adubação foi determinada conforme os atributos químicos do solo e as exigências nutricionais da cultura, segundo a recomendação de Aquino et al. (1993). Foi aplicado o equivalente a $150 \mathrm{~kg}$ de $\mathrm{N} \mathrm{ha}^{-1}, 100 \mathrm{~kg}$ de $\mathrm{P}_{2} \mathrm{O}_{5}$ ha $^{-1}$ e $120 \mathrm{~kg}$ de $\mathrm{K}_{2} \mathrm{O} \mathrm{ha}^{-1}$ usando-se, como fontes de nutrientes, a ureia, fosfato monoamônio (MAP) e o sulfato de potássio, respectivamente. Os fertilizantes foram distribuídos por fertigação durante a fase vegetativa da cultura. Para suprir prováveis deficiências de micronutrientes foram aplicados, na fundação, $12 \mathrm{~kg} \mathrm{ha}^{-1} \mathrm{de}$ FTE - BR 12 (9\% Zn; 1,8\% B; 0,85\% Cu; 3\% Fe; 2,1\% Mn e $0,10 \% \mathrm{Mo}$ ) sendo $5 \mathrm{~g} \mathrm{~m}^{-1}$ linear ocasião em que se aplicou, ainda, o equivalente a $10 \mathrm{Mg} \mathrm{ha}^{-1}$ de esterco bovino curtido.

$\mathrm{O}$ efluente de esgoto doméstico tratado foi proveniente de domicílios do município de Aquiraz, CE. Para o tratamento do esgoto bruto utilizou-se o sistema de lagoas de estabilização composto de uma lagoa anaeróbia, uma facultativa e duas de maturação. A caracterização da água potável e do efluente de esgoto doméstico tratado está exposta na Tabela 3.

Foram adotados dois sistemas de irrigação por gotejamento independentes (um para irrigação com o efluente de esgoto doméstico tratado e o outro para irrigação com água potável) constituídos de: conjunto moto bomba de $5 \mathrm{cv}$; cabeçal de controle, constituído por filtro de disco, tomada de pressão e registros; tubulações, linha principal e linha de derivação, que continham um cavalete com hidrômetro; nas linhas laterais foram conectados gotejadores do tipo autocompensante, modelo Katif, com vazão média de $3,75 \mathrm{~L} \mathrm{~h}^{-1}$ a uma pressão de serviço de $100 \mathrm{kPa}$.

Durante os primeiros 52 dias após o plantio (DAP) todos os tratamentos receberam a mesma lâmina de irrigação, referente a $100 \%$ da evaporação medida em um tanque classe "A" (ECA) objetivando estabelecer uma uniformidade no estande. No entanto, desde o transplantio, cada unidade experimental foi irrigada com sua respectiva fonte hídrica, conforme o estabelecido durante o processo de planejamento experimental. As irrigações foram realizadas com turno de rega fixo de dois dias consecutivos. Após os 52DAP ocorreu diferenciação dos tratamentos lâminas de irrigação mediante a variação do tempo necessário para a aplicação das respectivas lâminas de irrigação, que era controlado de conformidade com a abertura e/ ou fechamento de registros instalados no início de cada unidade experimental.

Devido às altas precipitações registradas nos meses de maio de 2010 e entre janeiro e maio de 2011, as irrigações foram suspensas nesses períodos. As médias pluviométricas e as lâminas de irrigação mensais durante o período de condução do experimento, estão expostas na Figura 1. As irrigações foram totalmente suspensas em 13 de maio de 2011, ocasião em que a cana-de-açúcar completou 12 meses de cultivo para que, só a partir de então, houvesse acúmulo de açúcares caracterizando o alcance do estádio de maturação da cultura.

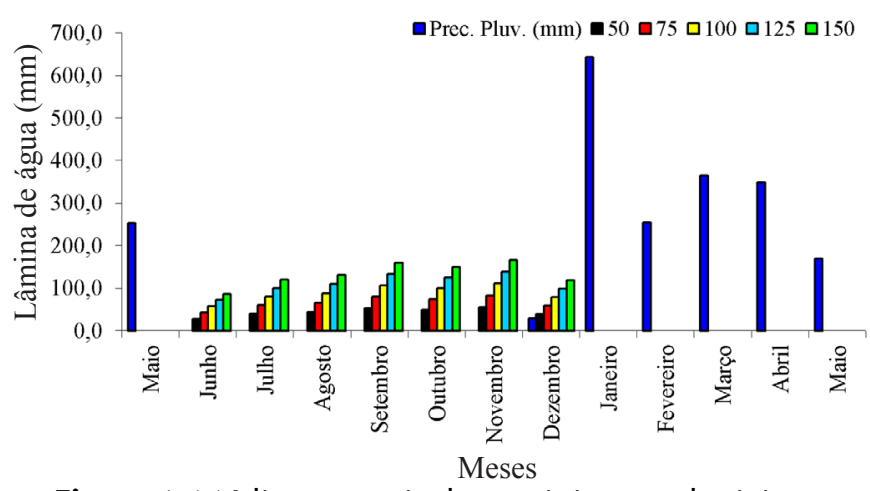

Figura 1. Médias mensais da precipitação pluviais registradas e das lâminas de irrigação aplicadas durante a condução do experimento no período de maio de 2010 a 7 de agosto de 2011

Com o intuito de executar a colheita da cana-de-açúcar 12 meses após o plantio, a partir de março de 2011, o conteúdo de sólidos solúveis totais ( ${ }^{\circ} \mathrm{Brix}$ ) foi monitorado com o auxílio de um refratômetro portátil, em intervalos regulares de 15 dias. As precipitações ocorridas entre os meses de março e maio prolongaram o período vegetativo da cultura atrasando o início do período de maturação. Assim, a colheita e a coleta dos dados produtivos foram realizadas em 7 de agosto de 2011 (15 meses após plantio) utilizando-se a metodologia adotada por Gonçalves (2010). As variáveis analisadas foram: densidade de plantas ou de colmos (plantas ha- ${ }^{-1}$ ); potencial produtivo de colmos $\left(\mathrm{Mg} \mathrm{ha}^{-1}\right)$; sólidos solúveis totais do caldo ( ${ }^{\circ}$ Brix) e potencial produtivo de etanol $\left(\mathrm{m}^{3} \mathrm{ha}^{-1}\right)$. Para verificar a influência de uma possível contaminação da cana irrigada com efluente de esgoto doméstico tratado na produção de etanol, determinou-se o rendimento de etanol por meio de fermentação em função da concentração alcoólica por volume de caldo. As análises foram realizadas no Laboratório de Bioengenharia: Sistemas Microbianos, do Departamento de Engenharia

Tabela 3. Características das águas potável e do efluente de esgoto tratado usadas na irrigação da cana-de-açúcar (Saccharum oficinarum L.) ${ }^{1}$

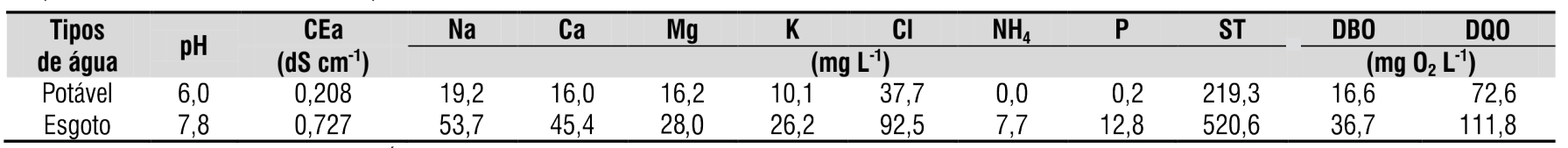

${ }^{1}$ Análises realizadas no Laboratório de Solos e Água do Departamento de Ciências do Solo da UFC 
Química da Universidade Federal do Ceará. Utilizou-se, para o processo fermentativo das amostras, o micro-organismo comercial Saccharomyces cerevisae (Fleichmann, Fermentec) em uma concentração inicial de $10 \mathrm{~g} \mathrm{~L}^{-1}$. As amostras foram diluídas pela metade da sua concentração inicial de açúcares, seu $\mathrm{pH}$ foi ajustado para 4,5 e as amostras foram autoclavadas a $110{ }^{\circ} \mathrm{C}$, durante $10 \mathrm{~min}$. Os processos foram realizados em batelada e conduzidos em mesa rotativa sendo a rotação de 150 $\mathrm{rpm}$ e a temperatura de $30{ }^{\circ} \mathrm{C}$. Alíquotas foram retiradas em intervalos de tempo pré-estabelecidos e analisados a produção de células (por turbidimetria a $660 \mathrm{~nm}$ em espectrofotômetro) a produção de etanol e o consumo de sacarose no CLAE (Cromatógrafo líquido de alta eficiência) equipado com um detector de índice de refração e com uma coluna Aminex HPX$87 \mathrm{H}$ utilizando-se $\mathrm{H}_{2} \mathrm{SO}_{4} 5 \mathrm{mmol} \mathrm{L}^{-1}$ como fase móvel na vazão de $0,5 \mathrm{~mL} \mathrm{~min}^{-1}$ a $65^{\circ} \mathrm{C}$.

Os dados das características avaliadas foram submetidos à análise de variância pelo teste F a 0,01 e 0,05 de probabilidade. Quando verificado efeito significativo na análise de variância, os dados obtidos nos diferentes tratamentos de natureza qualitativa (tipos de água) foram comparados através do teste de Tukey em nível de 0,01 e 0,05 de probabilidade enquanto os de natureza quantitativa (lâminas de irrigação) foram submetidos ao estudo de regressão utilizando-se, para isto, o software para análises estatísticas Assistat 7.6 Beta, da Universidade Federal de Campina Grande, PB (Silva \& Azevedo, 2009).

\section{Resultados E Discussão}

O resumo das análises das variâncias para os dados de potencial produtivo de colmos (PP), densidade de plantas (DP), conteúdo de sólidos solúveis totais (BX) e potencial produtivo de etanol (PPE) pode ser observado na (Tabela 4). Pelos resultados, verificou-se efeito significativo dos tipos de água em todas as variáveis analisadas. Houve efeito significativo dos tratamentos lâminas de irrigação nas variáveis (PP e DP). Ocorreu interação significativa do tipo de água $\mathrm{x}$ lâminas de irrigação (A x B) para o PP e DP, revelando a dependência entre esses fatores.

A maior média de potencial produtivo de colmo $(245,37$ $\mathrm{Mg} \mathrm{ha}{ }^{-1}$ ) foi observada para a cana-de-açúcar irrigada com efluente de esgoto doméstico tratado diferenciando-se estatisticamente $(\mathrm{p}<0,01)$ do PP obtido para a cana irrigada com água potável $\left(177,48 \mathrm{Mg} \mathrm{ha}^{-1}\right)$, diferença que pode estar associada aos nutrientes presentes no efluente de esgoto doméstico (Tabela 5). Sousa et al. (2009) também constataram, trabalhando com a cultura da mamona, produtividade superior para a mamona irrigada com esgoto doméstico tratado.

Tabela 5. Médias de potencial produtivo (PP) em função de dois tipos de água para irrigação e lâminas de água (L)

\begin{tabular}{cccccc}
\hline Tipo de & \multicolumn{5}{c}{ Lâminas de irrigação (\% ECA) } \\
\cline { 2 - 6 } água & $\mathbf{L 1}$ & $\mathbf{L 2}$ & $\mathbf{L 3}$ & $\mathbf{L 4}$ & $\mathbf{L 5}$ \\
& $\mathbf{5 0}$ & $\mathbf{7 5}$ & $\mathbf{1 0 0}$ & $\mathbf{1 2 5}$ & $\mathbf{1 5 0}$ \\
Potável & $116,40 \mathrm{bD}$ & $160,6 \mathrm{bC}$ & $189,7 \mathrm{bB}$ & $210,5 \mathrm{bA}$ & $210,2 \mathrm{bA}$ \\
Esgoto & $212,43 \mathrm{aB}$ & $219,9 \mathrm{aB}$ & $257,7 \mathrm{aA}$ & $264,6 \mathrm{aA}$ & $272,1 \mathrm{aA}$ \\
\hline
\end{tabular}

${ }^{1}$ Médias seguidas da mesma letra maiúscula nas linhas e minúscula nas colunas não diferem estatisticamente pelo teste de Tukey a $5 \%$ de probabilidade

O potencial produtivo da cana-de-açúcar irrigada com efluente de esgoto está condizente com o observado por Gomes et al. (2009) de 148,48 $\mathrm{Mg} \mathrm{ha}^{-1}$. Esses autores constataram, por meio da análise foliar, que o efluente de esgoto de esgoto doméstico tratado utilizado como fonte hídrica supriu totalmente as necessidades nutricionais de fósforo e enxofre da cultura.

Dalri et al. (2008) observaram, trabalhando com a canade-açúcar variedade RB 72454 sob irrigação por gotejamento subsuperficial, em Botucatu, SP, produtividade média de 300 $\mathrm{Mg} \mathrm{ha}{ }^{-1}$ superando o PP observado na presente pesquisa. Esta diferença está relacionada às divergências existentes entre as condições climáticas predominantes nas regiões com as divergências genéticas que são inerentes às variedades $\mathrm{e}$ condições edáficas uma vez que, segundo os autores, o solo em questão foi classificado como Nitossolo Vermelho.

O tratamento L5 (150\% ECA) da irrigação com efluente de esgoto doméstico tratado proporcionou maior PP de 272,1 $\mathrm{Mg} \mathrm{ha}^{-1}$, diferenciando-se estatisticamente dos obtidos com L1 e L2, também irrigados com efluente de esgoto doméstico tratado e de todos os PP obtidos com água potável (L1, L2, L3, L4 e L5) (Tabela 5). Deon et al. (2010) também observaram que o máximo potencial produtivo de $148,89 \mathrm{Mg} \mathrm{ha}^{-1}$ foi obtido com o maior tratamento de lâmina de efluente de esgoto doméstico tratado, referente a $200 \%$ da evapotranspiração da cultura.

Leal et al. (2009) observaram, trabalhando com a cana-deaçúcar irrigada com efluente de esgoto doméstico tratado nos níveis de irrigação correspondentes a 100, 125, 150 e $200 \%$ da demanda hídrica da cultura, uma produtividade máxima de $247 \mathrm{Mg} \mathrm{ha}^{-1}$, com a lâmina de água equivalente a $100 \%$ da

Tabela 4. Resumo da análise da variância para os dados de potencial produtivo (PP), densidade de plantas (DP), conteúdos de sólidos solúveis totais (BX) e potencial produtivo de etanol (PPE) de cana-de-açúcar sob dois tipos de água de irrigação (A) e cinco lâminas de irrigação (L)

\begin{tabular}{|c|c|c|c|c|c|}
\hline \multirow{2}{*}{$\begin{array}{l}\text { Fonte de } \\
\text { variação }\end{array}$} & \multirow{2}{*}{ G.L. } & \multicolumn{4}{|c|}{ Quadrados médios } \\
\hline & & PP & DP & BX & PPE \\
\hline Bloco & 3 & $154,677 \mathrm{~ns}$ & $4912252,96 n s$ & $2,858 \mathrm{~ns}$ & 1,34387 ns \\
\hline Trat. (A) & 1 & $46094,832^{* *}$ & $2650115061,22^{\star \star}$ & $0,196 \mathrm{~ns}$ & $239,00791 * *$ \\
\hline Resíduo A & 3 & 17,82529 & 4026555 & 2,045 & 6,29625 \\
\hline Parcelas & 7 & & & & \\
\hline Trat. (L) & 4 & $8762,525^{\star \star}$ & $1618755126,88^{\star *}$ & $2,415^{\star \star}$ & 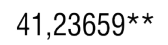 \\
\hline Int. AxL & 4 & 546,656 ** & $135612515,48 * *$ & $0,597 \mathrm{~ns}$ & $7,63573^{*}$ \\
\hline Resíduo L & 24 & 68,85897 & 10633492,67 & 0,525 & 1,88497 \\
\hline Total & 39 & & & & \\
\hline
\end{tabular}

A - Tipo de águas; L - Lâminas de irrigação; ns - não significativo; * - significativo a 0,05 de probabilidade; ** - significativo a 0,01 de probabilidade pelo teste $\mathrm{F}$ 
reposição hídrica sendo esta a mais recomendada pelos referidos autores visando ao manejo da irrigação da cultura. Este valor de produtividade de colmos se aproxima do observado no presente trabalho, de $257,7 \mathrm{Mg} \mathrm{ha}^{-1}$, obtido com $100 \%$ da ECA, para irrigação com efluente de esgoto doméstico tratado.

Para a cana-de-açúcar irrigada com água potável o máximo PP, de aproximadamente $211,7 \mathrm{Mg} \mathrm{ha}^{-1}$, foi estimado com lâmina de irrigação referente a $892 \mathrm{~mm}$ (Figura 2); a partir de então, o aumento da disponibilidade hídrica proporcionaria decréscimo no potencial produtivo de colmos. Sousa et al. (1999) também observaram uma resposta quadrática da produtividade de colmos da cana-de-açúcar em função da disponibilidade hídrica sendo que as máximas produtividades de 155,$8 ; 126,9$ e $141,9 \mathrm{Mg} \mathrm{ha}^{-1}$, prospectadas para as variedades RB72454, RB765418 e SP701011, respectivamente, foram estimadas com as lâminas totais de água 1.568, 1.424 e 1.589 $\mathrm{mm}$, respectivamente.

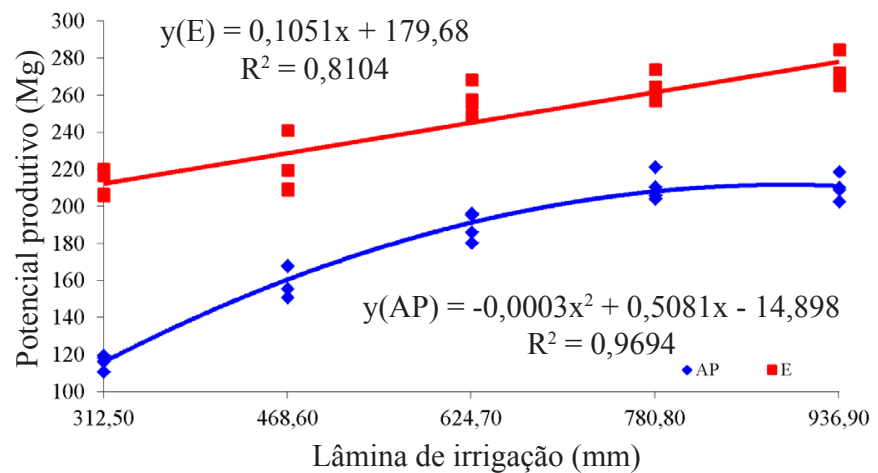

Figura 2. Potencial produtivo de cana-de-açúcar (S. officinarum L.) em função das lâminas de irrigação para água potável (AP) e efluente de esgoto doméstico tratado $(\mathrm{E})$

O incremento linear do PP em função do aumento das lâminas de irrigação provenientes de efluente de esgoto doméstico tratado, observado no presente ensaio (Figura 2) condiz com Deon et al. (2010). Segundo os autores, o incremento linear da produtividade em função do aumento das lâminas de irrigação se deve sobremaneira aos teores de nitrogênio presentes no efluente de esgoto doméstico tratado. Dantas Neto et al. (2006) concluíram, trabalhando com a cana-de-açúcar sob diferentes lâminas de irrigação $(807,986$, 1164 e $1343 \mathrm{~mm}$ ) e doses crescentes de $\mathrm{N}$ e $\mathrm{K}$, que as doses de fertilizantes exerceram efeitos mais significativos sob as variáveis agronômicas da cultura em detrimento da própria influência das variações de irrigação; ainda segundo os autores, a produtividade máxima de $104,0 \mathrm{Mg} \mathrm{ha}^{-1}$ foi obtida com a lâmina de irrigação referente a $1.164 \mathrm{~mm}$.

$\mathrm{O}$ efluente de esgoto doméstico tratado proporcionou um incremento médio de 66,53 $\mathrm{Mg} \mathrm{ha}^{-1}$ (Figura 2) ao se comparar os pontos de máximas produtividades de colmos estimados para os dois tipos de água utilizados na irrigação. Desta forma, o efluente de esgoto doméstico tratado usado para fins de irrigação é potencialmente capaz de incrementar o PP da cana-de-açúcar produzida no estado do Ceará.

A maior média de densidade de plantas - DP (115.920 plantas ha-1) foi obtida com a irrigação com efluente de esgoto doméstico tratado sendo superior estatisticamente $(p<0,05)$ à média observada para a cana-de-açúcar irrigada com água potável, que foi de aproximadamente 99.642 plantas ha ${ }^{-1}$ (Tabela 6).

Tabela 6. Médias de densidade de plantas (DP) em função de dois tipos de água para irrigação e lâminas de água (L)

\begin{tabular}{|c|c|c|c|c|c|}
\hline \multirow[b]{2}{*}{$\begin{array}{l}\text { Tipo de } \\
\text { água }\end{array}$} & \multicolumn{5}{|c|}{ Lâminas de irrigação (mm) - \% ECA } \\
\hline & $\begin{array}{l}\text { L1 } \\
50\end{array}$ & $\begin{array}{l}\mathrm{L} 2 \\
75\end{array}$ & $\begin{array}{l}\text { L3 } \\
100\end{array}$ & $\begin{array}{c}\mathrm{L} 4 \\
125\end{array}$ & $\begin{array}{c}\text { L5 } \\
150\end{array}$ \\
\hline
\end{tabular}

Potável 72.222 bD 92.416 bC 101.875 bB 116.416 bA 115.278 bA Esgoto $100.187 \mathrm{aD} 112.222 \mathrm{aC} \quad 118.055 \mathrm{aBC} 123.139 \mathrm{aAB} \quad 126.000 \mathrm{aA}$

${ }^{1}$ Médias seguidas da mesma letra maiúscula nas linhas e minúscula nas colunas não diferem estatisticamente pelo teste de Tukey a $5 \%$ de probabilidade

A maior DP observada para cana-de-açúcar irrigada com água potável foi obtida com o L4, de 116.416 plantas ha $^{-1}$ não se diferenciando estatisticamente da obtida com o L5. Esta foi superior às observadas por Dantas Neto et al. (2006) e por Silva et al. (2009b) que foram de 91.204 e 91.944 plantas $\mathrm{ha}^{-1}$, respectivamente, ambas para a variedade SP791011, cultivadas no município de Capim, PB, sob irrigação e turno de rega fixo de 12 dias, com lâminas totais de 1.164 e $1.065 \mathrm{~mm}$, respectivamente. Esta diferença na variável em questão pode estar relacionada ao menor intervalo entre as sucessivas irrigações adotado na presente pesquisa uma vez que o turno de rega foi fixado em 2 dias consecutivos. Por outro lado e corroborando com o presente trabalho, Dalri et al. (2008) observaram densidade média de 181.933 plantas ha ${ }^{-1}$ para cana-de-açúcar irrigada por gotejamento subsuperficial. Os autores também observaram maior densidade de plantas justamente para a mais alta frequência de irrigação, ou seja, no menor turno de rega.

Para cana-de-açúcar irrigada com efluente de esgoto doméstico tratado os tratamentos L4 e L5 proporcionaram as maiores DP diferenciando-se estatisticamente de L1, L2 e L3, para a cana-de-açúcar irrigada com a mesma fonte hídrica e de L1, L2, L3, L4 e L5 quando comparada com as DP médias obtidas com água potável.

$\mathrm{O}$ incremento quadrático estimado de acordo com a análise de regressão para a densidade de plantas em função do aumento das lâminas de irrigação, para os dois tipos de água de irrigação, se aproxima dos obtidos por Dantas Neto et al. (2006) que pesquisaram os efeitos de lâminas de irrigação $(807,986,1.164$ e $1.343 \mathrm{~mm})$ e doses de fertilizantes na canade-açúcar e observaram tendência de incremento quadrático da densidade de plantas em função do aumento das lâminas de irrigação. Segundo os referidos autores, as maiores densidades de plantas foram de $75.647 \mathrm{com} 986 \mathrm{~mm}$ e $91.204 \mathrm{com} 1.164$ $\mathrm{mm}$ para as adubações referentes a 85 e $305 \mathrm{~kg} \mathrm{ha}^{-1}$ da mistura, contendo $\mathrm{N} \mathrm{e} \mathrm{K}_{2} \mathrm{O}$ na proporção 1 para 0,94 , respectivamente (Figura 3).

Mota et al. (2010) trabalhando com o capim-elefante (Pennisetum purpureum, Schum) sob diferentes lâminas de irrigação $(0,20,40,80,100$ e $120 \%$ da evapotranspiração de referência - ETo) observaram uma resposta linear da densidade de plantas, em função da disponibilidade hídrica. 


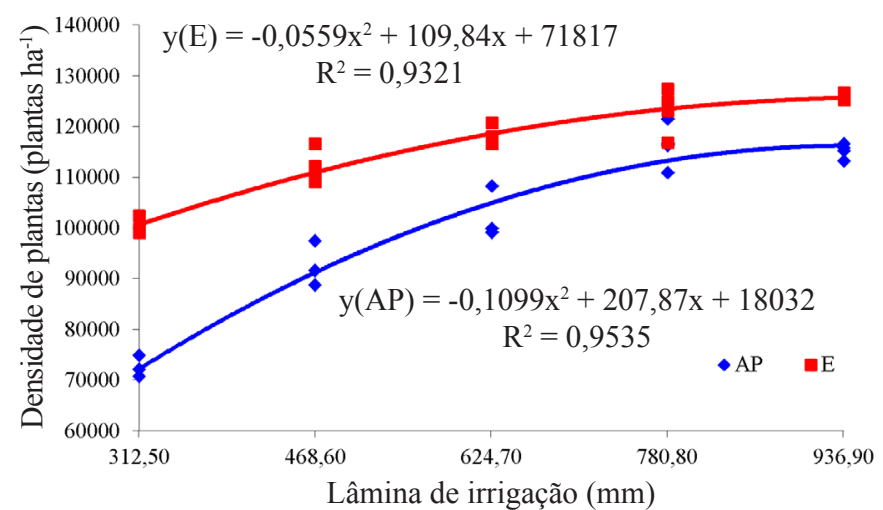

Figura 3. Densidade de plantas por hectare em função das lâminas de irrigação para água potável (AP) e efluente de esgoto doméstico tratado (E)

Não foram constatadas diferenças significativas $(p<0,05)$ dos tipos de água utilizados na irrigação quanto ao conteúdo de sólidos solúveis totais. Para a cana-de-açúcar irrigada com água potável a maior média $(18,83)$ foi obtida com L4 $(125 \%$ ECA) diferenciando-se estatisticamente das obtidas com L1, L2 e L3; não foi constatado diferença significativa entre as médias obtidas com L4 e L5 (Tabela 7). Corroborando com o presente trabalho, Farias et al. (2009) também observaram efeitos significativos da disponibilidade hídrica sob o conteúdo de sólidos solúveis totais; em função do máximo conteúdo de sólidos solúveis totais $\left({ }^{\circ} \mathrm{Brix}=20,37\right)$ foi obtido com a lâmina de irrigação referente a $100 \%$ da evapotranspiração da cultura (ETc). Já Dantas Neto et al. (2006) não constataram diferenças significativas do conteúdo de sólidos solúveis totais em função das lâminas de irrigação.

Tabela 7. Médias de sólidos solúveis totais ('Brix) em função de dois tipos de água para irrigação e lâminas de água (L)

\begin{tabular}{cccccc}
\hline \multirow{2}{*}{$\begin{array}{c}\text { Tipo de } \\
\text { água }\end{array}$} & $\mathbf{5 1}$ & $\mathbf{L 2}$ & $\mathbf{L 3}$ & $\mathbf{L} \mathbf{L}$ & $\mathbf{L 5}$ \\
& $\mathbf{5 0}$ & $\mathbf{7 5}$ & $\mathbf{1 0 0}$ & $\mathbf{1 2 5}$ & $\mathbf{1 5 0}$ \\
& \multicolumn{5}{c}{${ }^{\circ}$ Brix $(\%)$} \\
Potável & $17,17 \mathrm{~b}$ & $17,00 \mathrm{~b}$ & $17,17 \mathrm{~b}$ & $18,83 \mathrm{a}$ & $17,83 \mathrm{ab}$ \\
Esgoto & $17,17 \mathrm{a}$ & $17,17 \mathrm{a}$ & $17,17 \mathrm{a}$ & $17,73 \mathrm{a}$ & $18,07 \mathrm{a}$ \\
\hline
\end{tabular}

${ }^{1}$ Médias seguidas da mesma letra maiúscula nas linhas e minúscula nas colunas não diferem estatisticamente pelo teste de Tukey a 0,05 de probabilidade

Para a cana-de-açúcar irrigada com efluente de esgoto doméstico tratado não foram constatadas diferenças significativas sob a variável em questão. Essas respostas diferem das observadas por Assis et al. (2004) ao constatarem efeito significativo das diferentes lâminas de efluente de esgoto sobre o conteúdo de sólidos solúveis totais ( ${ }^{\circ}$ Brix) da cana-de-açúcar.

Embora o conteúdo de sólidos solúveis totais da canade-açúcar irrigada com os dois tipos de irrigação se tenha assemelhado estatisticamente, infere-se que o uso do efluente de esgoto doméstico tratado e o acréscimo da lâmina de irrigação se mostram como tratamentos vantajosos tendo em vista o ganho produtivo. Para Deon et al. (2010) os acréscimos produtivos proporcionados na irrigação com efluente de esgoto doméstico tratado superam a ligeira tendência de redução do conteúdo de sólidos solúveis totais proporcionados pelo aumento das lâminas totais de irrigação.
Na presente pesquisa não foi possível determinar um modelo matemático capaz de explicar o comportamento do conteúdo total de sólidos dissolvidos, frente às diferentes lâminas de irrigação evento que contrapõe os resultados obtidos por Farias et al. (2009), ao constatarem um comportamento linear desta variável em função de lâminas crescentes de irrigação.

A irrigação da cana-de-açúcar com efluente de esgoto doméstico tratado proporcionou o maior potencial produtivo médio de etanol $\left(14,65 \mathrm{~m}^{3} \mathrm{ha}^{-1}\right)$ diferenciando-se estatisticamente de $8,36 \mathrm{~m}^{3} \mathrm{ha}^{-1}$ obtido com a cana-de-açúcar irrigada com água potável (Tabela 8). O maior potencial produtivo de etanol observado para cana-de-açúcar irrigada com efluente de esgoto doméstico tratado se deve, provavelmente, aos nutrientes presentes no efluente de esgoto doméstico tratado. Dantas Neto et al. (2006) constataram efeitos significativos do aumento das doses de nitrogênio e potássio sob rendimento de álcool.

Tabela 8. Médias de potencial produtivo de etanol (PPE) em função de dois tipos de água para irrigação e lâminas de irrigação (L)

\begin{tabular}{|c|c|c|c|c|c|}
\hline \multirow[b]{2}{*}{$\begin{array}{l}\text { Tipo de } \\
\text { água }\end{array}$} & \multicolumn{5}{|c|}{ Lâminas de irrigação - \% ECA } \\
\hline & $\begin{array}{l}\text { L1 } \\
50\end{array}$ & $\begin{array}{l}\mathrm{L} 2 \\
75\end{array}$ & $\begin{array}{c}\text { L3 } \\
100\end{array}$ & $\begin{array}{r}\text { L4 } \\
125\end{array}$ & $\begin{array}{c}\text { L5 } \\
150\end{array}$ \\
\hline & \multicolumn{5}{|c|}{ Rendimento de álcool $\left(\mathrm{m}^{3} \mathrm{ha}^{-1}\right)$} \\
\hline Potável & $5,69 \mathrm{bC}$ & $7,57 \mathrm{bBC}$ & $8,36 \mathrm{bBC}$ & 9,49 bAB & 12,26 aA \\
\hline Esgoto & $9,86 \mathrm{aC}$ & $12,53 \mathrm{aBC}$ & $14,65 \mathrm{aAB}$ & $16,51 \mathrm{aA}$ & $14,27 \mathrm{aAB}$ \\
\hline
\end{tabular}

${ }^{1}$ Médias seguidas da mesma letra maiúscula nas linhas e minúscula nas colunas não diferem estatisticamente pelo teste de Tukey a $5 \%$ de probabilidade

O potencial produtivo médio de etanol obtido para cana-deaçúcar irrigada com água potável $\left(8,36 \mathrm{~m}^{3} \mathrm{ha}^{-1}\right)$ foi semelhante à média observada por Dantas Neto et al. (2006) porém, segundo os autores, não houve efeito significativo das diferentes lâminas de irrigação sobre o rendimento bruto de etanol, divergindo do presente trabalho, em que foi constatado efeito significativo da disponibilidade hídrica sobre o potencial produtivo de etanol. Esta diferença pode estar associada à irregularidade das precipitações pluviométricas já que os referidos autores constataram precipitação total de $807 \mathrm{~mm}$ distribuídos durante 10 meses, registrando apenas 2 meses sem chuva. Os maiores potenciais produtivos de etanol obtidos para cana-de-açúcar irrigada com água potável, de 9,49 e 12,26 $\mathrm{m}^{3} \mathrm{ha}^{-1}$, foram observados nos tratamento L4 e L5, respectivamente; já para a cana-de-açúcar irrigada com efluente de esgoto doméstico tratado o tratamento $\mathrm{L} 4=125 \%$ da ECA $(781,40 \mathrm{~mm})$ proporcionou um rendimento maior de $16,51 \mathrm{~m}^{3} \mathrm{ha}^{-1}$ embora não se tenha constatado diferença significativa entre os potenciais produtivos de etanol observados para os tratamentos L3, L4 e L5 (Tabela 8).

Azevedo (2002) também constatou efeito significativo das lâminas de irrigação no rendimento bruto de etanol. O máximo rendimento de álcool de $11,5 \mathrm{~m}^{3}$ ha $^{-1}$, obtido com lâmina de irrigação de $1.043 \mathrm{~mm}$, observado pelos referidos autores, está condizente com o máximo de $12,26 \mathrm{~m}^{3} \mathrm{ha}^{-1}$ encontrado na presente pesquisa com a lâmina $937,60 \mathrm{~mm}$ para a cana-deaçúcar irrigada com água potável.

Carvalho et al. (2009) também observaram efeitos significativos das lâminas de irrigação sobre o rendimento de etanol em que o máximo, de aproximadamente $9,80 \mathrm{~m}^{3} \mathrm{ha}^{-1}$, foi 
obtido com lâmina de irrigação referente a 393,0 mm, associado a uma precipitação pluviométrica de $755 \mathrm{~mm}$, totalizando $1.168 \mathrm{~mm}$ de água. O rendimento máximo de álcool observado pelos referidos autores foi semelhante ao denotado no presente trabalho, de $9,49 \mathrm{~m}^{3} \mathrm{ha}^{-1}$ para a irrigação com água potável, com uma lâmina de irrigação referente a $125 \%$ da ECA $(781,40$ $\mathrm{mm}$ ) o que, mais uma vez, pode estar relacionado aos menores intervalos entre irrigações adotados na presente pesquisa, ao serem equiparados com os adotados por Carvalho et al. (2009).

De acordo com as análises de regressão o modelo matemático linear foi o que melhor se ajustou ao potencial produtivo de álcool da cana-de-açúcar irrigada com água potável; já para a cana-de-açúcar irrigada com efluente de esgoto doméstico tratado o modelo matemático quadrático foi o que melhor se ajustou aos dados (Figura 4).

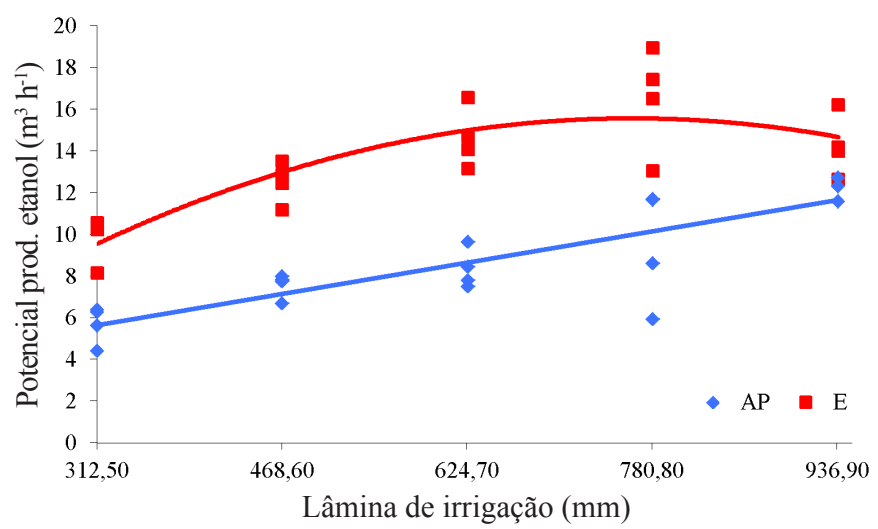

Figura 4. Potencial produtivo de etanol por hectare em função das lâminas de irrigação para água potável (AP) e efluente de esgoto doméstico tratado (E)

Carvalho et al. (2009) observaram um comportamento quadrático do rendimento bruto de álcool em função das crescentes lâminas de irrigação. Os máximos potenciais produtivos de álcool estimados para a cana-de-açúcar irrigada com água potável e efluente de esgoto doméstico tratado, de 11,68 e $15,57 \mathrm{~m}^{3} \mathrm{ha}^{-1}$, respectivamente, foram prospectados com as lâminas de irrigação de 937,60 e 764,20 mm, respectivamente (Figura 4).

O rendimento máximo de etanol estimado para cana-deaçúcar irrigada com água potável aproximou-se da média de 10,44 $\mathrm{m}^{3} \mathrm{ha}^{-1}$, observada por Azevedo (2002).

Os maiores valores de PPE estimados para a cana-deaçúcar irrigada com efluente de esgoto doméstico tratado em relação à cana-de-açúcar irrigada com água potável, são devidos, provavelmente, à capacidade do efluente de esgoto doméstico tratado de favorecer os aspectos nutricionais da cultura da cana-de-açúcar. Dos resultados, constata-se que houve incrementos de aproximadamente 36 e 17\% no PPE para a cana-de-açúcar irrigada com água potável e efluente de esgoto doméstico, respectivamente, quando comparados com os máximos rendimentos de etanol estimados com as lâminas 937,60 e 764,20 mm e os estimados com a lâmina 312,50 mm (Figura 4). Dantas Neto et al. (2006) também constataram, favorecendo a disponibilidade hídrica e utilizando adubação de $157 \mathrm{~kg}$ de $\mathrm{N}$ associado a $148 \mathrm{~kg}$ de $\mathrm{K}_{2} \mathrm{O}$ ha $^{-1}$, incrementos do rendimento de etanol. Os autores observaram incrementos de $30 \%$ quando comparados os rendimentos de etanol obtidos com as lâminas 807 e 1.164 mm.

Comparando os máximos rendimentos estimados de etanol nas duas fontes hídricas, constatou-se um incremento aproximado de $33 \%$ para a cana-de-açúcar irrigada com efluente de esgoto doméstico (Figura 4).

\section{Conclusões}

1. A irrigação suplementar da cana-de-açúcar promove aumento na densidade de plantas no potencial produtivo de colmos e de etanol.

2. O aumento das lâminas de irrigação com água potável até $781 \mathrm{~mm}$ (125\% da ECA) proporciona incrementos no potencial produtivo, na densidade de plantas e no conteúdo de sólidos totais dissolvidos, sendo esta a mais apropriada para o cultivo da cana-de-açúcar nas condições nas quais se conduziu a presente pesquisa.

3. O efluente de esgoto doméstico tratado potencializa a produção de etanol da cana-de-açúcar.

4. A lâmina de irrigação com efluente de esgoto doméstico tratado de 764,2 $\mathrm{mm}$ distribuída durante todo o ciclo de desenvolvimento da cana-de-açúcar, é indicada para exploração da cultura visando à produção de etanol.

\section{Agradecimentos}

À Companhia de Água e Esgoto do Ceará (CAGECE) pelo apoio financeiro e estrutural a esta pesquisa e à FUNCAP, pela concessão da bolsa de estudo.

\section{Literatura Citada}

Aquino, A. B.; Aquino, B. F.; Hernandez, F. F. F.; Holanda, F J. M.; Freire, J. M.; Crisostomo, L. A.; Costa, R. I.; Uchôa, S. C. P.; Fernandes, V. L. B. Recomendações de adubação e calagem para o estado do Ceará. 1.ed. Fortaleza: UFC, 1993. 247p.

Assis, P. C. de O.; Lacerda, R. D. de; Azevedo, H. M. de; Dantas Neto, J.; Farias, C. H. de A. Resposta dos parâmetros tecnológicos da cana-de-açúcar a diferentes lâminas de irrigação e adubação. Revista de Biologia e Ciências da Terra, v.4, p.1519-1531. 2004.

Azevedo, H. M. de. Resposta da cana-de-açúcar a doses de irrigação e de adubação de cobertura nos tabuleiros costeiros da Paraíba. Campina Grande: UFCG, 2002. 112p. Tese Doutorado

Brasil. Ministério da Agricultura, Pecuária e Abastecimento. Companhia Nacional de Abastecimento. Acompanhamento da safra brasileira cana-de-açúcar: Safra 2012/13: segundo levantamento: Agosto 2012. Brasília, 2012. http://www.conab. gov.br/OlalaCMS/uploads/ arquivos/12_08_15_07_05_boletim_cana_portugues_agosto_2012_2o ${ }^{\circ}$ lev.pdf. 7 Ago. 2012.

Carvalho, C. M. de; Azevedo, H. M. de; Dantas Neto, J.; Farias, C. H. de A.; Silva, C. T. S.; Gomes Filho, R. R.. Rendimento de açúcar e álcool da cana-de-açúcar submetida a diferentes níveis de irrigação. Revista Brasileira de Ciências Agrárias, v.4, p.72-77, 2009. 
Dalri, A. B.; Cruz, R L.; Gracia, C. J. B.; Duenhas, L. H. Irrigação de gotejamento subsuperficial na produção e qualidade da cana-de-açúcar. Revista Irriga, v.13, p.1-11, 2008.

Dantas Neto, J.; Figueredo, J. L. da C.; Farias, C. H. de A.; Azevedo, H. M. de; Azevedo, C. A. V. de. Resposta da canade-açúcar, primeira soca, a níveis de irrigação e adubação de cobertura. Revista Brasileira de Engenharia Agrícola e Ambiental, v.10, p.283-288, 2006.

Deon, M. D.; Gomes, T. M.; Melfi, A. J.; Montes, C. R.; Silva, E. da. Produtividade e qualidade da cana-de-açúcar irrigada com efluente de estação de tratamento de esgoto. Pesquisa Agropecuária Brasileira, v.45, p.1149-1156, 2010.

EMBRAPA - Empresa Brasileira de Pesquisa Agropecuária. Centro Nacional de Pesquisa de Solos. Sistema brasileiro de classificação de solos. 2. ed. Rio de Janeiro: EMBRAPA, 2006. 306p.

Farias, C. H. de A.; Fernandes, P. D.; Gheyi, H. R.; Dantas Neto, J. Qualidade industrial de cana-de-açúcar sob irrigação e adubação com zinco, em Tabuleiro Costeiro paraibano. Revista Brasileira de Engenharia Agrícola e Ambiental, v.13, p.419-428, 2009.

Freitas, C. A. S. de; Silva, A. R. A. da; Bezerra, F. M. L.; Ferreira, C. da S.; Andrade, R. R. de. Crescimento vegetativo da cana-de-açúcar (Saccharum officinarum L.)irrigada com água de esgoto doméstico tratado. Conexões Ciência e Tecnologia, v.6, p.27-43, 2012.

Gomes, T. M.; Melfi, A. J.; Montes, C. R.; Silva, E. da; Sundefeld Júnior, G. C.; Deon, M. D.; Piveli, R. P. Aporte de nutrientes e estados nutricional da cana-de-açúcar irrigada com efluente de estação de tratamento de esgoto com e sem desinfecção. Revista DAE, v.60, p.19-25, 2009.

Gonçalves, F. M. Evapotranspiração e coeficientes de cultivo da cana-de-açúcar irrigada por gotejamento subsuperficial. Fortaleza: UFC, 2010. 65p. Dissertação Mestrado
Leal, R. M. P.; Firme, L. P.; Monte, C. R.; Melfi, A. J.; Piedade, S. M. de S. Soil exchangeable cations, sugarcane production and nutrient uptake after wastewater irrigation. Scientia Agricola, v.66, p.242-249, 2009.

Maule, R. F.; Mazza, A. J.; Martha Júnior, G. R. Produtividade agrícola de cultivares de cana-de-açúcar em diferentes solos e épocas de colheita. Scientia Agrícola, v.58, p.295-301, 2001.

Mota, V. J. G.; Reis, S. T. dos; Sales, E. C. J. de; Rocha Júnior, V. R.; Oliveira, F. G. de; Walker, S. F.; Martins, C. E.; Coser, A. C. Lâminas de irrigação e doses de nitrogênio em pastagem de capim-elefante no período seco do ano no norte de Minas Gerais. Revista Brasileira de Zootecnia, v.39, p.1191-1199, 2010.

Silva, A. B. da; Dantas Neto, J.; Farias, C. H. de A.; Azevedo, C. A. V. de; Azevedo, H. M. de. Rendimento e qualidade da cana-de-açúcar irrigada sob adubações de nitrogênio e potássio em cobertura. Revista Caatinga, v.22, p 236-241, 2009a.

Silva, C. T. S. da; Azevedo, H. M. de; Azevedo, C. A. V. de; Dantas Neto, J.; Carvalho, C. M. de; Gomes Filho, R. R. Crescimento da cana-de-açúcar com e sem irrigação complementar sob diferentes níveis de adubação de cobertura nitrogenada e potássica. Revista Brasileira de Agricultura Irrigada, v.3, p.3-12, 2009b.

Silva, F. de A. S.; Azevedo, C. A. V. de. Principal components analysis in the software Assitat-Statistical attendance. In: World Congress on Computers in Agriculture, 7, Proceedings... American Sociey of Agricultural and Biological Engineers, Reno-NV-USA, 2009.

Sousa, E. F.; Bernardo, S.; Carvalho, J. A. Função de produção da cana-de-açúcar em relação água para três variedades, em Campos dos Goytacazes, RJ. Engenharia Agrícola, v.19, p.28-42, 1999. 